\title{
Legal Issues Involved in E-Commerce
}

\author{
By M Ali Nasir
}

The exponential growth of the Internet and online activity raise a number of new regulatory issues and legal questions.

The power of the Web to reach the world carries with it a variety of legal issues, often related to intellectual property concerns, copyright, trademark, privacy, etc., particularly in the context of doing business on the Internet. Authorities seeking to apply their laws in traditional ways or to expand legal control over international links face many challenges due to the global nature of the Internet. This paper provides an overview of some of the legal issues and related problems in e-commerce.

\section{Introduction}

Approximately 100 countries now enjoy Internet access, and a recent survey reported that there are approximately 20 million Internet hosts worldwide. The number of Internet users is currently estimated to be in the region of 100 million people [1].

The exponential growth of the Internet and online activity raise a number of new regulatory issues and legal questions. How does copyright apply to digital content? How can national laws apply to activities in cyberspace? Can privacy and data protection exist on the Web? Can electronic commerce really be secure? Should governments tax cyber trade? Can cyberspace be regulated by one, or by many authorities? In seeking to apply the law to the Internet, 
problems arise owing to the fact that most laws largely apply to the pre-cyberspace world.

In the modern era of electronic technology, many people want to get their work done quickly with little effort. At times, people forget or do not consider the legal and ethical values of their procedures. In traditional commerce, it's not easy to start a business. You must implement strategies that follow rules and regulations enforced by government. Electronic commerce makes it possible to do almost any kind of business in a very simple way. What makes it simple? The reason is that existing legal frameworks and enforcement mechanisms are not strong.

E-commerce presents a world of opportunity for doing businesses, reaching global markets and purchasing without leaving the home or office. E-commerce can provide opportunities to improve business processes, just as phones, faxes and mobile communications have in the past. However, just as any new business tool has associated issues and risks so does e-commerce. It's important to understand the legal issues and potential risks to ensure a safe, secure environment for trading with customers and other businesses.

The issue of law on the Internet is a complex one. Between the two all-or-nothing extremes lies a broad spectrum of possibilities [2]. Many people revel in the freedom to express themselves and the freedom from prohibitions such as zoning restrictions that the Internet apparently affords. With no law at all, however, the Internet would be no place to conduct business or pleasure. Laws give people certainties about their rights and responsibilities: they make life more predictable. "Without predictability, business will not 
be able to act efficiently, or price services effectively," said Thomas Vartanian, a Washington, D.C.-based lawyer [2].

\section{Electronic Transaction}

Some federal, state and territory governments encourage the adoption of electronic commerce by enacting and enabling legalisation. In Australia many bills and acts have been passed to resolve legal issues and make electronic transaction more authenticated, such as the Electronic Transaction Act (ETA)[3]. ETA enables contractual dealings, such as offers, acceptances and invitations, to be conducted electronically, and also allows people to use an electronic signature to satisfy any legal requirement. Even the electronic transfer of land is covered, "Importantly, the Act is similar in all material respects to those operating both in other States and at the Federal level, so people can be confident that electronic transactions carry the same legal weight nationwide," states Jim McGinty, Attorney General for Western Australia [4].

Moreover the bill is expected to boost electronic commerce as an effective tool for businesses to increase their efficiency. This may reduce administrative duties, storage and operational costs for businesses. In McGinty's words," This is why it is crucial that we ensure the legal infrastructure around cyberspace is beyond doubt" [4].

New legislation brings some questions such as, for how long will these acts be valid? What are the boundaries of these acts? Who should be forced to follow the rules? Most of these questions are unanswerable today. 
Global companies have the responsibility to deal with some of the legal issues such as how to form contracts, abide by consumer protection laws, create privacy policies and protect databases. "As of now, there is no comprehensive set of laws or regulations that exist for international electronic commerce," says David D. Barr [5]. He added that it is difficult to establish uniform worldwide laws for e-commerce, but some building block legislation within individual countries is necessary.

By applying laws and sketching boundaries around the borderless Internet do we negate the term "freedom of information"? How will legal structure affect international transactions on the Internet? Will it restrict the potential growth of the Internet prematurely? Rapid changes in technology do not allow enforcement of specific laws in cyberspace. For now many organizations are promoting global coordination of legal structures [5].

\section{Privacy \& Security}

While shopping on the Internet, most people typically do not think about what is happening in the background. Web shopping is generally very easy. We click on a related site, go into that site, buy the required merchandise by adding it to our cart, enter our credit card details and then expect delivery within a couple of days. This entire process looks very simple but a developer or businessmen knows exactly how many hurdles need to be jumped to complete the order. Customer information has to pass through several hands so security and privacy of the information are a major concern. The safety and security of a customer's personal information lies within the hands of the business. Therefore businesses have to give the customer first their guarantee, and second peace of mind, that the information passed over is of no risk to any invading eyes. 
In traditional and online trading environments, consumers are entitled to have their privacy respected. Websites should provide the customers with choices regarding the use of their personal information, and incorporate security procedures to limit access to customer information by unauthorised parties. Privacy policies and procedures should be clearly explained to customers. Although respecting consumer privacy rights is a legal requirement, it also represents good business practice. If customers trust a site and business then they are more likely to trade with it.

Many people are not willing to disclose their personal information on the Web. It is up to individuals to decide how much personal information they are willing to disclose and how it might be used. Interestingly, one survey found that many people who disclose personal information do so in hope of financial benefit, such as winning a sweepstakes. [6]

\section{Copyright \& Trademark}

Many attempts have been made to address the issues related to copyrights on digital content. E-commerce has a tremendous impact on copyright and related issues, and the scope of copyrights is affecting how e-commerce evolves. It is essential that legal rules are set and applied appropriately to ensure that digital technology does not undermine the basic doctrine of copyright and related rights. From one perspective, the Internet has been described as "the world's biggest copy machine" [7]. Older technologies such as photocopying, recording and taping are bound by rules and regulations regarding quantity, content, quality and time constraints. In contrast, on the Internet one person can send 
Generally, a trademark can be owned by an individual, a company, or any sort of legal entity. When someone else tries to use that trademark (e.g., your distinctive name or logo) without authorisation, it could be considered an illegal dilution of the distinctive trademark. If someone uses a trademark in such a way as to dilute the distinctive quality of the mark or trade on the owner's reputation, the trademark owner may seek damages.

Some Web-based applications have enabled large-scale exploitation of music samples and audio formats. Software that is available free of cost on the Net allows the transfer of songs and videos without the authorization of rights holders (e.g. Napster, MP3 Providers). Moreover, CD burners and portable MP3 players allow copyright violations to occur rather easily.

A number of important recent developments have occurred in the field of copyright and related issues that have far-reaching implications for the industry, and are being addressed in legislatures, judiciaries and international forums. During the last couple of years, new laws have passed in some countries to ensure effective protection and enforcement of rights in the digital era. At the same time, copyright industries are also adapting their business methods and uses of technology to exploit digital opportunities, while guarding against new risks.

A Pew Research Center survey, conducted among roughly 2,500 Americans through March and May 2003, indicates that 35 million US adults download music files online and about 26 million share files online. The downloading population has grown by approximately 5 million users since February of 2001 [9] 
"Ultimately, the music industry's war on illegal downloading can never be won" say Charles Shoniregun [10].

\section{Online Terms, Conditions, Policies and Laws}

At the moment, most online privacy policies are produced by private businesses for individual companies. Governments are developing legislation to support and strengthen the privacy protection measures of many businesses. These initiatives are aimed at regulating the storage, use and disclosure by businesses of personal information.

Privacy legislation is designed to protect a person's personal information. The privacy laws of their host country affect overseas companies. Every organisation should be very careful while applying terms and conditions for the electronic transaction for Internet users. Privacy and security policies not only reflect the organizations practice but also the rules and regulations for doing business with the company. Major issues regarding the legalization of electronic transactions include the following.

-- Ensure proper online contracts.

-- Record retention obligations.

-- Original documentation, in terms of TAX and VAT requirements.

-- Import/export regulations.

-- Exchange control regulation.

-- Foreign data protection law.

\section{Legislation Dilemma}


Electronic transactions separate e-business from traditional types of businesses. When a transaction takes place, Who has jurisdiction? Who has the authority to apply law over the transaction?

For example, if you buy a laptop in your local computer store, you know your legal rights. If the computer does not work when you take it home, and the store refuses to settle up, then you can probably take the dispute to your local small claims court. But if you buy the same computer online, from a vendor on the other side of the world, perhaps through a dealer based in yet a third country, then your rights are a lot less clear. Which country's protection laws apply: yours, those in the vendor's home country, or those of the intermediary? Without knowing which particular set of laws apply, it's impossible to know whom to sue. "Small claims courts don't work in cyberspace," according to Ron Presser of the American Bar Association. [2]

A little legislation can go a long way toward helping parties to establish better boundaries to work within. When a transaction that takes place between two different parties located in two different countries goes wrong then a number of complex questions arise.

This is not the first time the question of extra-territorial jurisdiction over Web content has been raised. In November of last year, Felix Somm, ex-manager of CompuServe Deutschland, was cleared on appeal of pornography charges brought against him in Germany after newsgroups carried on parent company CompuServe's US servers were found to contain pornographic material. The judge determined that it was technically impossible for Somm to close the illegal newsgroups in question [2]. Following in the footsteps of the CompuServe's case, Yahoo is arguing that it would be technically 
impossible to block only French citizens from access to its online auctions if should the auctions contain objectionable items.

\section{E-Business and Legal Issues}

The technological basis of e-commerce is basically Web client/server middleware, or what is called three-tier architectures. The client tier is the Web browser involving some type of form processing. The middle tier is the Web server, often with transaction processing. The Web server in turn links to the third tier, a database processing the order information. Some of the issues are strictly Internet-related, such as domain names and trademarks, linking and framing, clickware (and shrinkware), and metatag use. Others are traditional issues applied to the Internet, such as copyright, contracts, consumer protection, privacy, taxation, regulated industries and jurisdiction.

E-commerce site development, its advertising, electronic transaction, money transactions and such involve many legal issues, which need to be taken into account step by step. Before developing an e-commerce site a registered domain and a registered trademark should be established. There must be some copyright protection on the site. The business must ensure that it displays the terms and condition/policies within its site. Security involving the privacy of a user's data is always one of the main concerns while doing business online. Defining rules and regulations for the advertisement of the site by placing banners on other known sites is another. It is of great value when dealing with such complex issues to consult an attorney who specializes in the issues of cyberspace. 


\section{Conclusion}

Most of the legal issues surrounding electronic commerce are not new. Lawyers should, however, be able to recognise the increased significance of certain legal issues to the online environment. In understanding the technical, contractual, intellectual property and regulatory issues, which have enhanced importance in the new economy, the lawyer is well placed to assist clients in pro-actively minimising their exposure to legal liability.

Before allocating resources to the initiative it must be determined whether it is legally possible to perform the business process or transaction electronically. For example, the Electronic Communication and Transaction (ECT) Act facilitates the conclusion of most transactions and communications electronically by placing such transactions on an equal footing with traditional transactions or communications.

The popular view of the Internet as an unregulated medium is not true. The laws of the world's jurisdiction still apply when you surf the Net: the only difference is that the way they might apply. The colonisation of cyberspace is both technology and opportunity driven. Indeed technology is at the same time both a threat as well as a solution, because on the one hand it challenges existing legal and regulatory infrastructures and yet offers the solution to many of those threats, including security, integrity and authenticity.

\section{References}

1. Bond, Robert "International Legal Issues of E-Commerce" Legal Updates, http://www.faegre.com, 2003. 
2. Sayer, Peter and Deveaux, Sarah "Jurisdiction in Cyberspace" IDG News Service Friday, July 28, 2000 see also http://www.pcworld.com

3. Western Australia Dept of Industry and Resources, http://www.law.gov.au/www/securitylawHome.nsf/

4. McGinty, Jim http://www.ministers.wa.gov.au

5. Barr, David D. "The Need of a Broad Standard in Global ECommerce" The Internet Law Journal, Dec. 26, 2000

6. "Law, Ethics and Cyber Crime" Prentice Hall 2003

7. "Its the World's Biggest Copy Machine," PC Week, January 27, 1997.

8. "Intellectual Property on the Internet", A survey of issues. [Copyrights and Related Issues], http://ecommerce.wipo.int/survey/

9. Greenspan, Robyn "Downloaders Disregard Legal, Copyright Issues", http://www.internetnews.com, August 1, 2003. 10. Shoniregun, C.A., "Intellectual Property Rights of Multimedia Enriched Websites", Communication of the ACM: Ubiquity, Volume 3, Issue 37, Oct 29. (2002).

M Ali Nasir enjoys exploring new technologies. He completed bachelor and master degrees in computer sciences in Pakistan. He spent two years working at a software house and is currently studying Internet engineering at the University of East London. 